\title{
Myeloid cell subsets dynamic during progression of mouse collagen-induced arthritis
}

\author{
J Presumey ${ }^{1,2^{*}}$, C Jorgensen ${ }^{1,2,3}$, G Courties ${ }^{1,2}$, F Apparailly ${ }^{1,2,3}$ \\ From 5th European Workshop on Immune-Mediated Inflammatory Diseases \\ Sitges-Barcelona, Spain. 1-3 December 2010
}

\section{Introduction}

Circulating monocytes consist at least of two main subsets of immune cells arising from a common progenitor in the bone marrow that can give rise to macrophages and dendritic cells (DCs) upon entry into tissues [1]. These cells represent a prominent component of immune infiltrates during the progression of immune-mediated inflammatory disorders (IMID). Over the past years, multiple cell surface markers have been used in attempt to define monocytes, leading to the identification of several subpopulations. In many models of infections and IMID, the so-called inflammatory monocytes CD11b+ Ly6C+ have been shown to traffic to sites of inflammation and lymph nodes, differentiating into inflammatory DCs in situ. A splenic "reservoir" of monocytes able to migrate into injured tissues to regulate inflammation has also been recently described [3].

\section{Aim}

The present study aimed at better characterizing monocytes subsets and monocyte-derived cells during the development of autoimmune arthritis in mice.

\section{Methods}

Using flow cytometric immunophenotyping, we have analyzed the expression of several specific myeloid cell markers, CD11b, Ly6C, Ly6G, CD43, CD115, F4/80, CD11c, PDCA1, CMHII during mouse collagen-induced arthritis. We have specified the frequencies of the various cell subpopulations in the blood, spleen, draining lymph nodes and inflamed joints at different stages of the pathology, compared to naïve mice.

\section{Results}

As previously reported, percentages of whole blood monocytes increased with disease progression from less

${ }^{1}$ Inserm, U 844, Montpellier, France

Full list of author information is available at the end of the article than $10 \%$ up to $25 \%$. Locally, the number of neutrophils increased from $\sim 30 \%$ up to $\sim 60 \%$ in the CIA joints compared with steady state and represent the main source for local TNF- $\alpha$ production. Surprisingly, monocytes are found in significant amount within steady state joints $(\sim 2 \%)$ and their number increased during CIA ( $\sim 5 \%$ of total cells). Finally, the subpopulation of Ly6 $\mathrm{C}^{\mathrm{low}}$ monocytes observed in steady state conditions switched toward Ly6 $\mathrm{C}^{\text {int/high }}$ monocytes in CIA joints and produces high levels of TNF- $\alpha$, compared with naïve mice.

\section{Conclusion}

Overall, our data show that monocytes are not only present within blood and lymphoid organs as previously described, but also within joints, in both steady state and pathological conditions. Although not fully differentiated, these cells with inflammatory phenotype are present within CIA joints.

\section{Author details}

'Inserm, U 844, Montpellier, France. ${ }^{2}$ Université Montpellier1, UFR de Médecine, Montpellier, France. ${ }^{3} \mathrm{CHU}$ Lapeyronie, Service Clinique d'ImmunoRhumatologie, Montpellier, France.

Published: 25 November 2010

\section{References}

1. Geissmann F, Manz MG, Jung S, Sieweke MH, Merad M, Ley K: Development of monocytes, macrophages, and dendritic cells. Science 2010, 327(5966):656-61.

2. Ziegler-Heitbrock L, Ancuta P, Crowe S, Dalod M, Grau V, Hart DN, et al: Nomenclature of monocytes and dendritic cells in blood. Blood 2010, ahead of print.

3. Swirski FK, Nahrendorf M, Etzrodt M, Wildgruber M, Cortez-Retamozo V, Panizzi $P$, et al: Identification of splenic reservoir monocytes and their deployment to inflammatory sites. Science 2009, 325(5940):612-6.

doi:10.1186/1479-5876-8-S1-P54

Cite this article as: Presumey et al:: Myeloid cell subsets dynamic during progression of mouse collagen-induced arthritis. Journal of Translational Medicine 2010 8(Suppl 1):P54. 